Revista Brasileira de Cartografia

ISSN 1808-0936 | https://doi.org/10.14393/revbrascartogr

Sociedade Brasileira de Cartografia, Geodésia, Fotogrametria e Sensoriamento Remoto

\title{
Análise Multicritério da Suscetibilidade à Erosão na Bacia Hidrográfica do Rio da Batateira, CE
}

\author{
Multicriteria Analysis of Erosion Susceptibility in the Batateira River Basin, CE
}

Rafaela Maria Rodrigues Tavares Agra ${ }^{1}$ e Claudia Daza Andrade ${ }^{2}$

1 Universidade Federal Rural do Rio de Janeiro, Departamento de Engenharia, Seropédica, Brasil. E-mail: rafaela.mrta@gmail.com ORCID: https://orcid.org/0000-0002-7022-3176

2 Universidade Federal Rural do Rio de Janeiro, Departamento de Engenharia, Seropédica, Brasil. E-mail: dazaclau@gmail.com ORCID: https://orcid.org/0000-0001-6074-152X

\begin{abstract}
Resumo: A bacia hidrográfica do rio da Batateira, localizada no sul cearense, está passando por um processo de erosão acelerado, devido ao uso inadequado do solo na área. Sendo assim, este trabalho objetivou o mapeamento da suscetibilidade à erosão na Bacia da Batateira, visando nortear o uso das terras e auxiliar na tomada de decisão quanto a identificação das áreas essenciais para a preservação do meio ambiente e das medidas de conservação. Foram usadas bases cartográficas da região para obtenção de camadas de informações espaciais (classes de solos, declividade, elevação, geologia, geomorfologia e uso/cobertura do solo) que foram cruzadas em ambiente SIG por meio de análise multicritério, para definir a vulnerabilidade erosiva da bacia. Os resultados obtidos mostraram que mais de 56\% da área em estudo apresenta forte suscetibilidade à erosão, marcada pela presença de vegetação florestal com áreas agrícolas, pastagem natural (caatinga), além de agropecuária, declividades acima de $20 \%$.
\end{abstract}

Palavras-chave: Erosão. Análise Multicritério. Bacia da Batateira.

\begin{abstract}
The catchment area of the Batateira river, located in southern Ceará, is undergoing an accelerated erosion process, due to the inadequate use of the soil in the area. Thus, this work aimed at mapping the susceptibility to erosion in the Batateira Basin, aiming to guide land use and assist decision making in identifying areas that are essential for the preservation of the environment and conservation measures. The cartographic bases of the region were used to obtain layers of spatial information (classes of soils, slope, elevation, geology, geomorphology and land use / cover) that were crossed in a GIS environment by means of multicriteria analysis to define the vulnerability of the basin. The results showed that more than $56 \%$ of the study area presents a strong susceptibility to erosion, marked by the presence of forest vegetation with agricultural areas, natural pasture (caatinga), and cattle ranching, declivities above $20 \%$ with red argisols, yellow latosols and quartzarenic neosols.
\end{abstract}

Keywords: Erosion. Multicriteria Analysis. Batateira Basin.

\section{INTRODUÇÃO}

O processo erosivo é um dos fatores com maior influência na degradação dos solos ao redor do mundo. Dessa forma, é importante que seja monitorado, já que afeta diretamente à capacidade produtiva dos solos e, em consequência, à segurança alimentar mundial (MANTOVANI et al., 2018; RICKSON et al., 2015).

A perda do solo reduz a fertilidade e os rendimentos das terras agrícolas. O carreamento do solo que foi removido contribui para a contaminação da água devido aos sedimentos suspensos, além disso, os sedimentos também podem provocar assoreamentos dos reservatórios e cursos d'água resultando na perda da capacidade de armazenamento, causando inundações nos períodos de intensas chuvas (SOCO, 2009).

A suscetibilidade do solo à ação erosiva é chamada de erodibilidade. A erodibilidade representa o efeito integrado dos processos que regulam a infiltração de água e a resistência do solo à desagregação e transporte. A erodibilidade é uma propriedade intrínseca do solo, bem como a textura, estrutura, permeabilidade, teor de matéria orgânica, argilominerais, teor de óxidos de ferro e alumínio (LAL, 1988).

De acordo com Basílio et al. (2019), as cartas de suscetibilidade aos movimentos de massa categorizam 
os terrenos quanto ao potencial de ocorrência de processos geológicos naturais e induzidos em áreas de interesse. Para a produção de tais cartas, ferramentas de geoprocessamento facilitam e agilizam o processo de construção dos mapas, já que, mediante sua capacidade de extrair, armazenar e manipular informações geoespaciais, é possível agregar diversos mapas temáticos, gerando assim, um aporte para a caracterização espacial e temporal das áreas vulneráveis aos processos erosivos. (FANTINEL; BENEDETTI, 2016; VALÉRIO et al., 1995).

A área de estudo escolhida para este trabalho é a bacia hidrográfica do rio da Batateira, situada na porção sul do Estado do Ceará, porção onde encontra-se a maior reserva de águas subterrâneas do Estado. O local de estudo apresenta um processo erosivo visível e intenso, uma vez que conjunturas do meio físico influenciam para tais processos.

Nesse sentido, o seguinte trabalho foi desenvolvido com o intuito de analisar o avanço da erosão no meio físico do entorno, levando em consideração as informações disponíveis e os dados cartográficos e bibliográficos levantados da área de estudo, bem como a escolha das variáveis a serem utilizadas para a ponderação da suscetibilidade à erosão. Pretende-se assim, contribuir, não apenas como base de conhecimento científico, tendo em vista que, foram encontrados poucos trabalhos referentes à erosão na região e com enfoque muito geral, como também, servir de suporte para o planejamento e melhor uso/ocupação da área, evitando assim problemas ambientais futuros, como assoreamento de rios e lagos, perda da fertilidade e produtividade do solo.

\subsection{Caracterização da área de estudo}

A bacia do rio da Batateira (Figura 1), abrange sete municípios, totalizando uma área de $1705,65 \mathrm{Km}^{2}$, integra parte da bacia hidrográfica do rio Salgado, que por sua vez, está inserida na maior reserva de águas subterrâneas do Estado do Ceará, localizada na bacia sedimentar do Araripe, pertencente ao sistema aquífero médio, que possui aproximadamente $500 \mathrm{~m}$ de espessura (SILVA, 2017). Na região existem rochas sedimentares que apresentam permeabilidade, as mesmas limitam o escoamento superficial e favorecem à alimentação dos aquíferos compensando a escassez ou ausência de rios pelo maior potencial de águas subterrâneas (FUNCEME,2009).

O clima é caracterizado por temperaturas médias anuais que variam entre $23^{\circ}$ e $27^{\circ}$, enquanto a umidade relativa do ar fica em torno de $50 \%$ no período seco e $80 \%$ na época de chuvas. A precipitação média anual varia entre 800 e $1200 \mathrm{~mm}$ ano- ${ }^{1}$, com regime bastante regular. Nos meses de janeiro a maio ocorre a principal estação chuvosa, responsável por aproximadamente $70 \%$ das chuvas anuais. O trimestre menos chuvoso é referente aos meses de agosto a outubro (FUNCEME, 2009). 
Figura 1 - Mapa de localização da área de estudo.
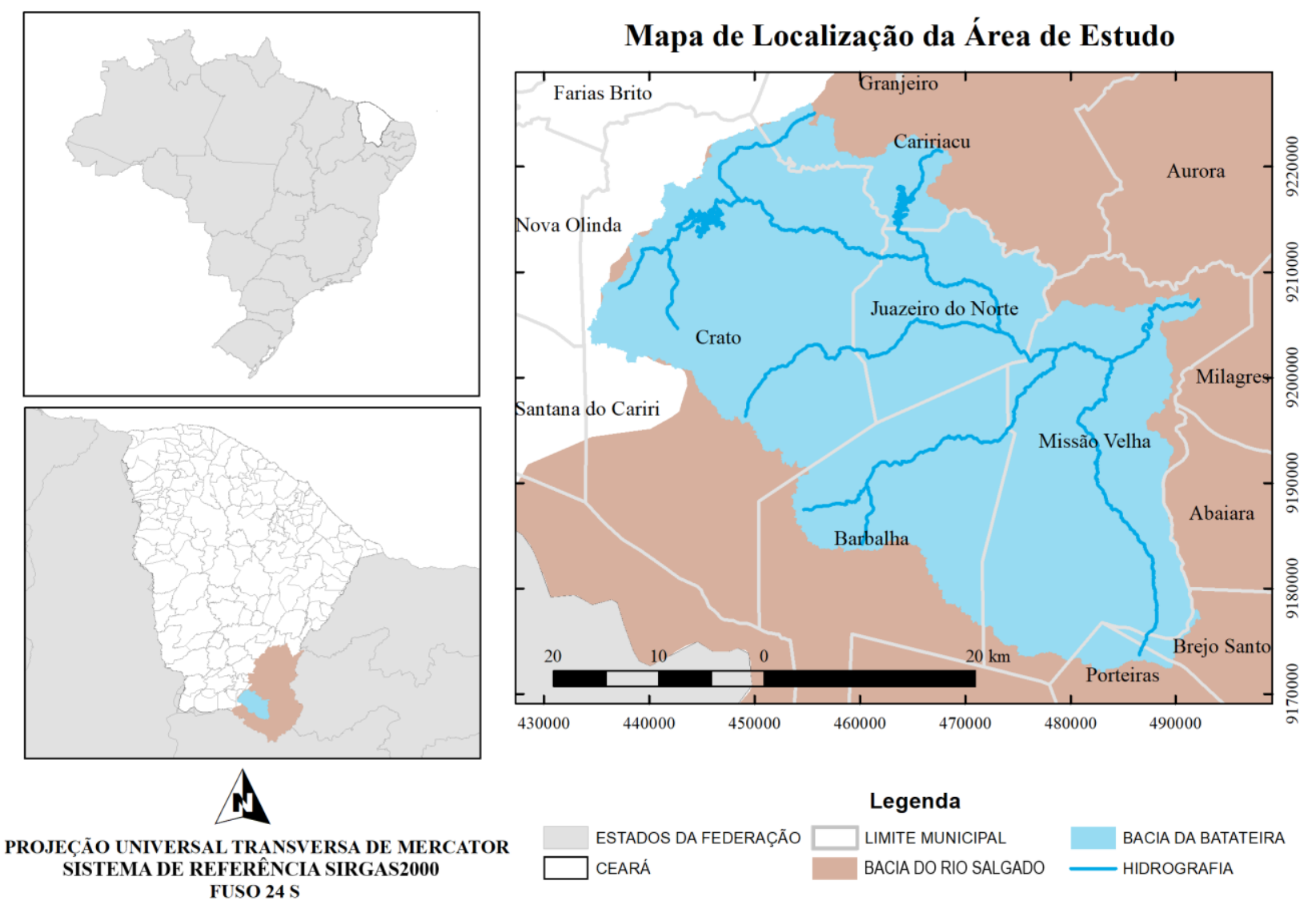

Fonte: Os autores (2021).

No local, há o predomínio de solos mais profundos com domínio de Latossolos derivados de arenito da Formação Exu. No sopé da chapada ${ }^{1}$, entorno de municípios como Crato, Juazeiro do Norte e Barbalha, predominam solos profundos avermelhados, com média fertilidade natural e boas condições para o uso agrícola. (FERREIRA et al., 2016; FUNCEME, 2009). A bacia encontra-se inserida na FLONA (Floresta Nacional do Araripe), relevante por ser uma das primeiras áreas protegidas do Brasil e a primeira Floresta Nacional do país.

\section{MATERIAIS E MÉTODOS}

Para a realização deste estudo foram levantadas e processadas informações bibliográficas e cartográficas relacionadas à região de interesse como base para a análise a ser realizada. A continuação, descrevem-se os dados utilizados e os procedimentos desenvolvidos para atingir o objetivo proposto.

\subsection{Dados cartográficos e mapas temáticos}

O levantamento de dados não foi uma tarefa simples, devido principalmente à escassez de dados cartográficos da região disponíveis ao público e em escalas adequadas para o estudo em questão. Os dados cartográficos utilizados neste estudo foram os seguintes:

\footnotetext{
${ }^{1}$ Chapada: “Denominação usada no Brasil para as grandes superfícies, por vezes horizontais e a mais de $600 \mathrm{~m}$ de altitude. Do ponto de vista geomorfológico a chapada é, na realidade, um planalto sedimentar, pois trata-se de um acamamento estratificado que, em certos pontos, está nas mesmas cotas da superfície de erosão, talhadas em rochas pré-cambrianas. ” (Minidicionário Geográfico Online)
} 
a) Mapa dos limites dos estados da federação e municipais - adquirido no banco de dados online do IBGE;

b) Imagens de radar SRTM (NASA) - adquiridas no banco de dados online do USGS, com resolução espacial de $30 \mathrm{~m}$, ano de 2017;

c) Mapa geológico - adquirido no banco de dados online do IBGE, escala de 1:250.000;

d) Mapa geomorfológico - adquirido no banco de dados online do IBGE, escala de 1:250.000;

e) Mapa de uso e cobertura do solo - adquirido no banco de dados online do IBGE, escala de 1:1.000.000;

f) Mapa de classes de solo - adquirido via solicitação de e-mail à FUNCEME (Fundação Cearense de Meteorologia e Recursos Hídricos), escala de 1:100.000, ano de 2012.

A adaptação dos mapas temáticos foi realizada no ArcGIS, desenvolvido pela ESRI versão 10.2, no qual foi criado um banco de dados geográficos para o processamento e o armazenamento das informações. Adotou-se o sistema de projeção UTM (Universal Transversa de Mercator) Zona 24 e Sistema de Referência SIRGAS2000.

Delimitou-se a Bacia hidrográfica do rio Batateiras a partir do Modelo Digital de Elevação - MDE da região, obtido pela NASA, por meio da Shuttle Radar Topography Mission - SRTM. A missão SRTM disponibiliza as cartas gratuitamente. Foram calculadas as declividades e a elevação por meio do MDE e para a definição da rede de drenagem foi utilizada a ferramenta Arc hydro do ArcGIS.

\subsection{Suscetibilidade erosiva}

A suscetibilidade erosiva foi definida como consequência de interposições de pesos em camadas das variáveis estudadas. Para definição das variáveis e dos pesos atribuídos, a metodologia apoiou-se em referências como Diniz et al. (2008); Ahmed (2009); Xavier et al. (2010); Valladares et al. (2012); Silveira (2014); Souza et al. (2015), em que notas de risco à degradação foram dadas às variáveis escolhidas.

Para cada mapa gerado atribuiu-se valores de influência de 0 a 100\% (Tabela 1) e seus pesos respectivos variando em uma escala de 0 a 10 em cada classe definida, levando em consideração as características físicas, antrópicas e a relevância de cada feição para ocorrência do processo erosivo da área de estudo. A posterior integração dos mapas foi realizada no ambiente do ArcGis com a conversão dos arquivos em formato vetorial para matricial.

O raster de declividade foi dividido de acordo com a Embrapa (1979), e assim como os demais rasters, os pesos aplicados aos seus respectivos atributos foram dados conforme à literatura utilizada, mencionada acima.

Tabela 1 - Porcentagem de influência das variáveis utilizadas com seus respectivos pesos atribuídos.

\begin{tabular}{c|c|c|c}
\hline Variáveis & Atributos & Influência & Peso \\
\hline \multirow{4}{*}{ Declividade } & Plano - $(0-3 \%)$ & & 1 \\
& Suave ondulado - $(3-8 \%)$ & 3 \\
& Ondulado - $(8-20 \%)$ & 5 \\
& Forte ondulado - $(20-45 \%)$ & $30 \%$ & 7 \\
& Montanhoso - $(45-75 \%)$ & \\
& Forte Montanhoso - $(>75 \%)$ & & 9 \\
\hline \multirow{3}{*}{ Elevação } & $900-1001 \mathrm{~m}$ & & 9 \\
& $800-900 \mathrm{~m}$ & & 8 \\
& $700-800 \mathrm{~m}$ & $05 \%$ & 7 \\
& $600-700 \mathrm{~m}$ & & 6 \\
& $500-600 \mathrm{~m}$ & & 5 \\
& $400-500 \mathrm{~m}$ & & 4 \\
& $<400 \mathrm{~m}$ & & 3 \\
\hline
\end{tabular}




\begin{tabular}{|c|c|c|c|}
\hline Variáveis & Atributos & Influência & Peso \\
\hline Uso e cobertura do Solo & $\begin{array}{c}\text { Área agrícola } \\
\text { Área urbana } \\
\text { Corpo D'água } \\
\text { Agropecuária com remanescentes florestais } \\
\text { Vegetação campestre com áreas agrícolas } \\
\text { Vegetação florestal com áreas agrícolas } \\
\text { Pastagem natural } \\
\end{array}$ & $20 \%$ & $\begin{array}{l}8 \\
3 \\
0 \\
6 \\
7 \\
5 \\
9\end{array}$ \\
\hline Geologia & $\begin{array}{c}\text { Aluviões Holocênicos } \\
\text { Cobertura Detrito-Laterítica Paleogênica } \\
\text { Complexo Caicó } \\
\text { Complexo Itaizinho } \\
\text { Formação Exu } \\
\text { Formação Mauriti } \\
\text { Formação Missão Velha } \\
\text { Formação Santana } \\
\text { Formação Santa dos Garrotes } \\
\text { Granitóides de Quimismo Indiscriminado } \\
\text { Corpo D’água }\end{array}$ & $10 \%$ & $\begin{array}{l}10 \\
9 \\
2 \\
2 \\
5 \\
6 \\
6 \\
7 \\
8 \\
1 \\
0\end{array}$ \\
\hline Geomorfologia & $\begin{array}{c}\text { Alinhamento de Cristas do Patamar Sertanejo } \\
\text { Chapada do Araripe com forma tabular } \\
\text { Chapada do Araripe com forma pediplana } \\
\text { Depressão do Cariri } \\
\text { Corpo D’água } \\
\end{array}$ & $15 \%$ & $\begin{array}{l}5 \\
7 \\
6 \\
6 \\
0\end{array}$ \\
\hline Classes de Solos & $\begin{array}{c}\text { Corpo D’água } \\
\text { Argissolo Vermelho-Amarelo eutrófico abrúptico } \\
\text { Neossolo Flúvico eutrófico } \\
\text { Latossolo Amarelo } \\
\text { Latossolo Vermelho-Amarelo } \\
\text { Área Urbana } \\
\text { Argissolo Vermelho } \\
\text { Argissolo Vermelho-Amarelo eutrófico } \\
\text { Neossolo Litólico distrófico } \\
\text { Neossolo Quartzarênico órtico distróficos } \\
\text { Neossolo Litólico eutrófico e distrófico } \\
\text { Neossolos Litólico eutrófico }\end{array}$ & $20 \%$ & $\begin{array}{c}0 \\
1 \\
1 \\
3 \\
3 \\
3 \\
5 \\
5 \\
5 \\
5 \\
8 \\
10\end{array}$ \\
\hline
\end{tabular}

Fonte: Os autores (2021).

\section{RESULTADOS E DISCUSSÕES}

Tendo em vista a avaliação da erodibilidade, utilizou-se a análise multicritério para combinar diversas informações importantes presentes no mapeamento de declividade, elevação, uso e cobertura, geologia, geomorfologia e tipo de solo. Dessa maneira, cada variável foi utilizada para elaborar o mapa de suscetibilidade à erosão de toda a região em estudo. A seguir são apresentadas as variáveis isoladamente e posteriormente o mapa de suscetibilidade gerado pela combinação das mesmas.

\subsection{Mapa da declividade}

A declividade da região é variada, observa-se que $11 \%$ da bacia apresenta regiões com inclinações de terreno superiores a $45 \%$. Estas áreas com declive acentuado possuem um escoamento superficial rápido sendo propensas à erosão. A área restante da bacia apresenta declividades de onduladas a planas (Figura 2). 
Figura 2 - Mapa de declividade.

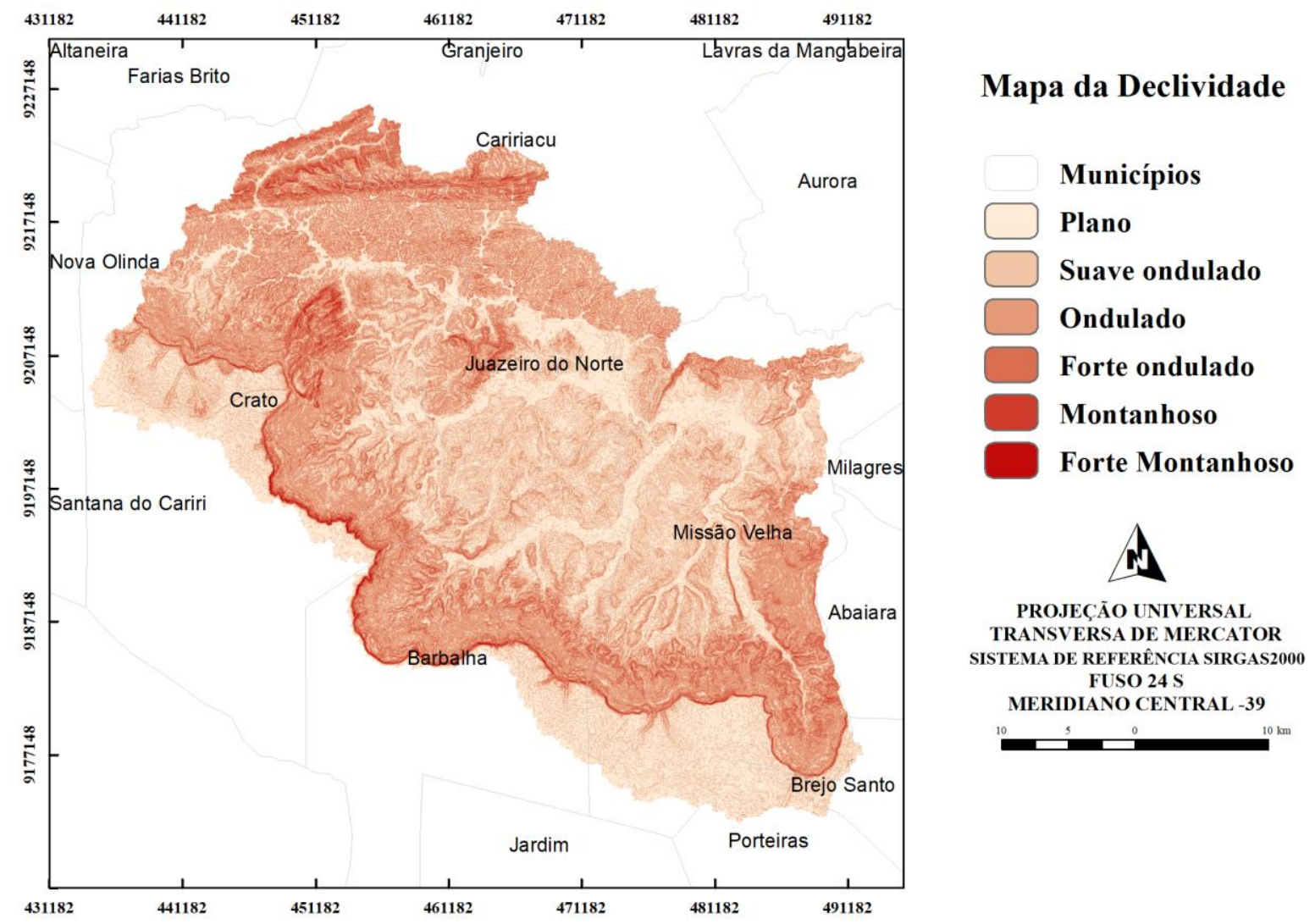

Fonte: Os autores (2021).

\subsection{Mapa da elevação}

Em questão de elevação (Figura 3), 19\% do local apresenta altitudes inferiores a 400 m; as áreas de $400 \mathrm{~m}$ a $600 \mathrm{~m}$ de altitude representam um pouco mais da metade da bacia. As zonas com altitudes acima dos $600 \mathrm{~m}$ representam quase $30 \%$ da área total. Quanto maior for a elevação do terreno maior será a velocidade da queda da água podendo provocar erosão pela enxurrada (EMBRAPA,2006). 
Figura 3 - Mapa de elevação.

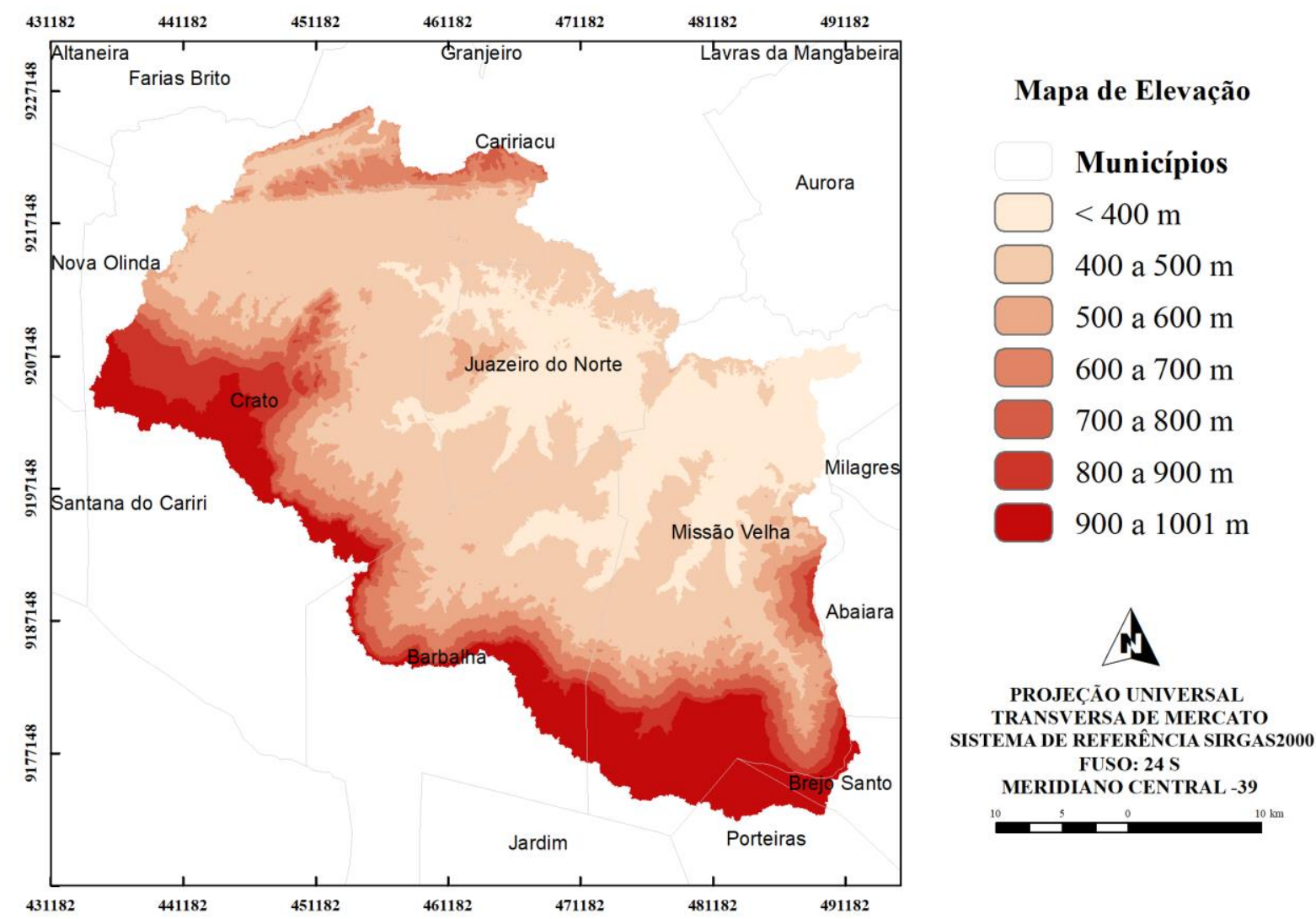

Fonte: Os autores (2021).

\subsection{Mapa de uso e cobertura de solo}

Na Figura 4 observa-se que as classes pastagem natural e área agrícola representam aproximadamente $39 \%$ da área da região. A pastagem natural retratada pela caatinga possui um solo descoberto com tendência à erosão, podendo agravar-se com chuvas e ventos intensos, fazendo com que dunas avancem sobre a vegetação, ocasionando a desertificação. As classes vegetação florestal com áreas agrícolas, agropecuária com remanescentes florestais e vegetação campestre totalizaram mais de $40 \%$ da área. 
Figura 4 - Mapa de uso e cobertura do solo.

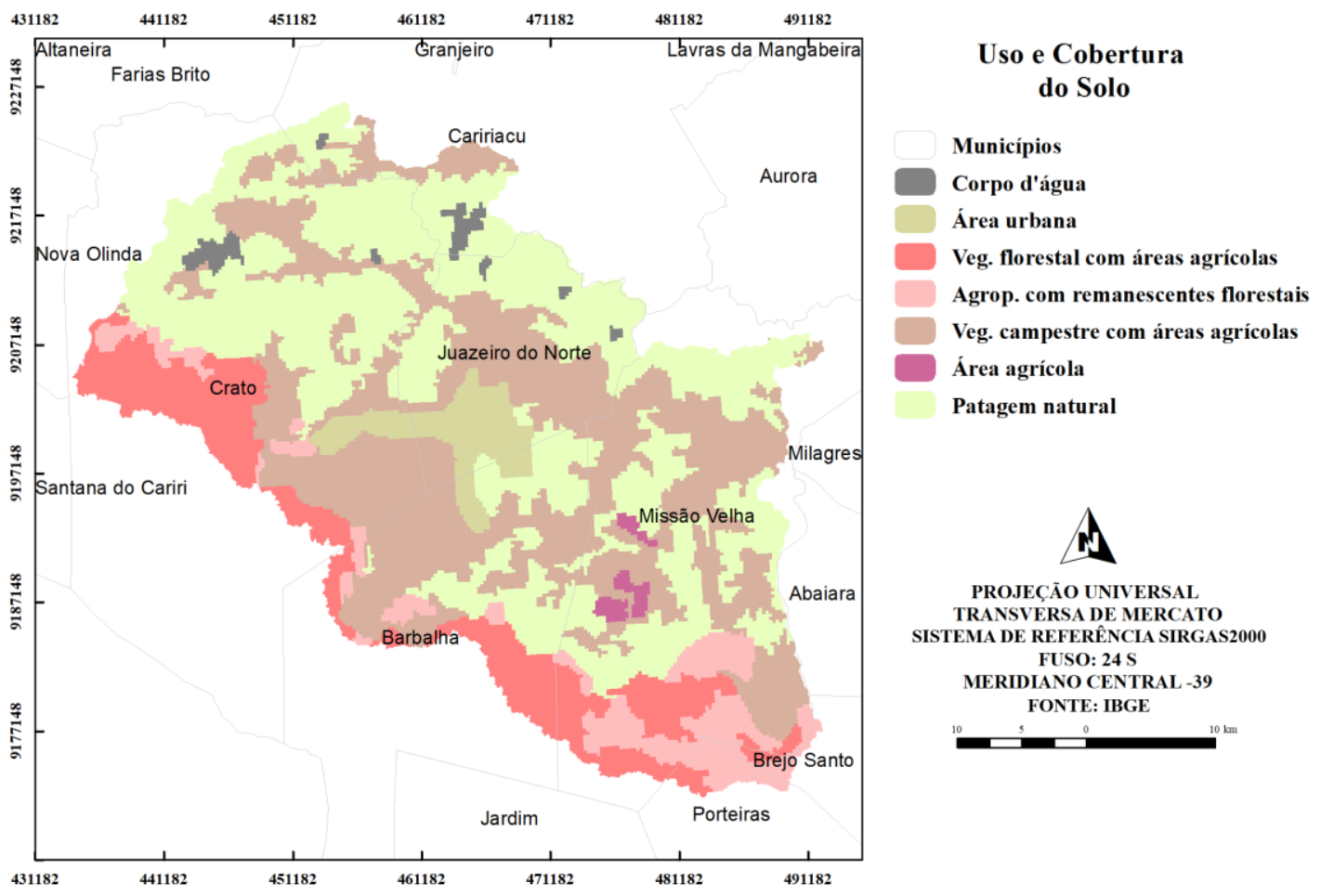

Fonte: Os autores (2021).

\subsection{Mapa Geológico}

A cobertura detrito laterítica paleogênica é composta por paleossolos, que se resumem em solos formados em condições no passado, caracterizando uma suscetibilidade a movimentos de massa bem significante.

Os aluviões holocênicos são constituídos por sedimentos inconsolidados, dominantemente arenosos, representados por areias, com níveis de cascalhos, lentes de material silto-argiloso e turfa, o que determina áreas com intensas vulnerabilidades à erosão, e ainda nessa mesma unidade há presença de falhas, aumentando o grau de suscetibilidade aos movimentos de massa.

Formação de Santana é composta basicamente por calcários e gipsita, unidades facilmente dissolvíveis, além dos folhelhos verdes e arenitos interestratificados, que possuem fácil rompimento e Formação Santana dos Garrotes apresenta muitas falhas geológicas, sendo que grande parte destas se intersectam entre si, gerando maiores áreas de fraqueza.

Formação Exu, caracterizada por compostos friáveis, ou seja, rompem-se facilmente, no entanto menos vulneráveis que as classes acima mencionadas. As unidades Formação Mauriti e Formação Missão Velha, que ocupam uma parte considerável da bacia, podem ser categorizadas como menos vulneráveis à erosão, entretanto apresentaram falhas geológicas, tornando-se grupos mais instáveis.

Já os granitoides de quimismo indiscriminado, Complexo Caicó e Complexo Itaizinho, são metagranitos arqueanos, ou seja, as formações mais antigas da área de estudo, rochas bem resistentes (Figura $5)$. 
Figura 5 -Mapa de geologia.

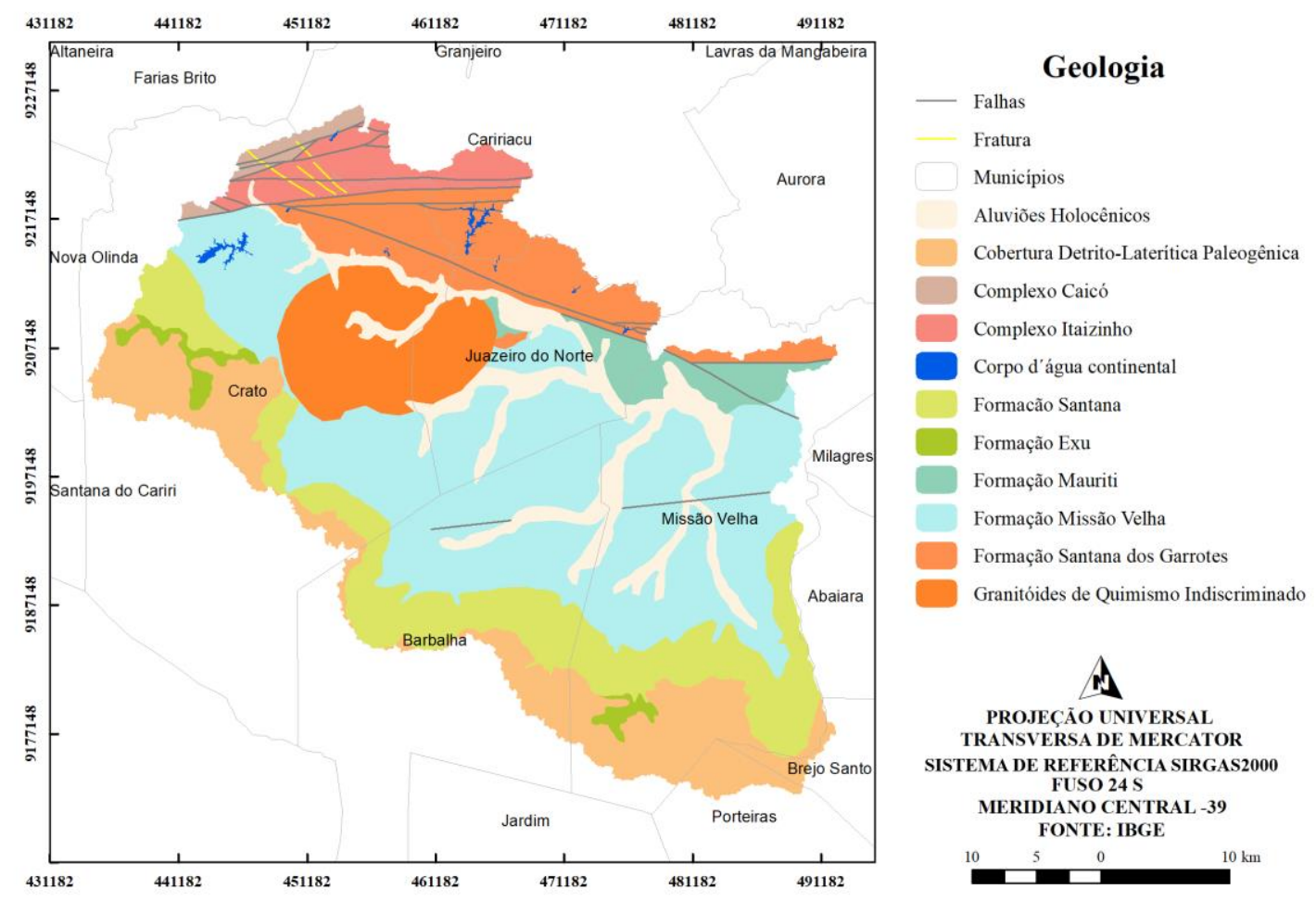

Fonte: Os autores (2021).

\subsection{Mapa Geomorfológico}

A classe alinhamento de cristas do patamar sertanejo representa, dentro do pacote sedimentar, as rochas que mais resistiram ao intemperismo e por isso se mantiveram alcançando altitudes maiores quando comparadas aos elementos adjacentes. No entanto, ainda assim sofreram desgastes por ação principalmente do vento e da água que resultou em diferenciadas formas de esculturas: algumas cristas tiveram seus topos aplainados resultando em chapadões (feição geomorfológica típica da Chapada do Araripe). Outros tiveram suas arestas erodidas até que o topo se tornasse convexo aparentando ligeiros morrotes areníticos, e todo o conjunto sofreu dissecação da encosta causada pela ação de cachoeiras temporárias que escoam pela face livre das elevações.

A Chapada do Araripe representa componentes geomorfológicos já escavados por ação erosiva que resultaram em grandes áreas aplainadas consideradas o assoalho da bacia estudada. Nestas localidades os elementos naturais desgastaram a rocha até o nível de base, destruindo os afloramentos rochosos e rebaixando a cota local, obtendo como produto extensas camadas de areia e material detrítico. A depressão do cariri sofreu dissecação superior às áreas do entorno, sendo rebaixada além do assoalho (Figura 6). 
Figura 6 -Mapa de geomorfologia.

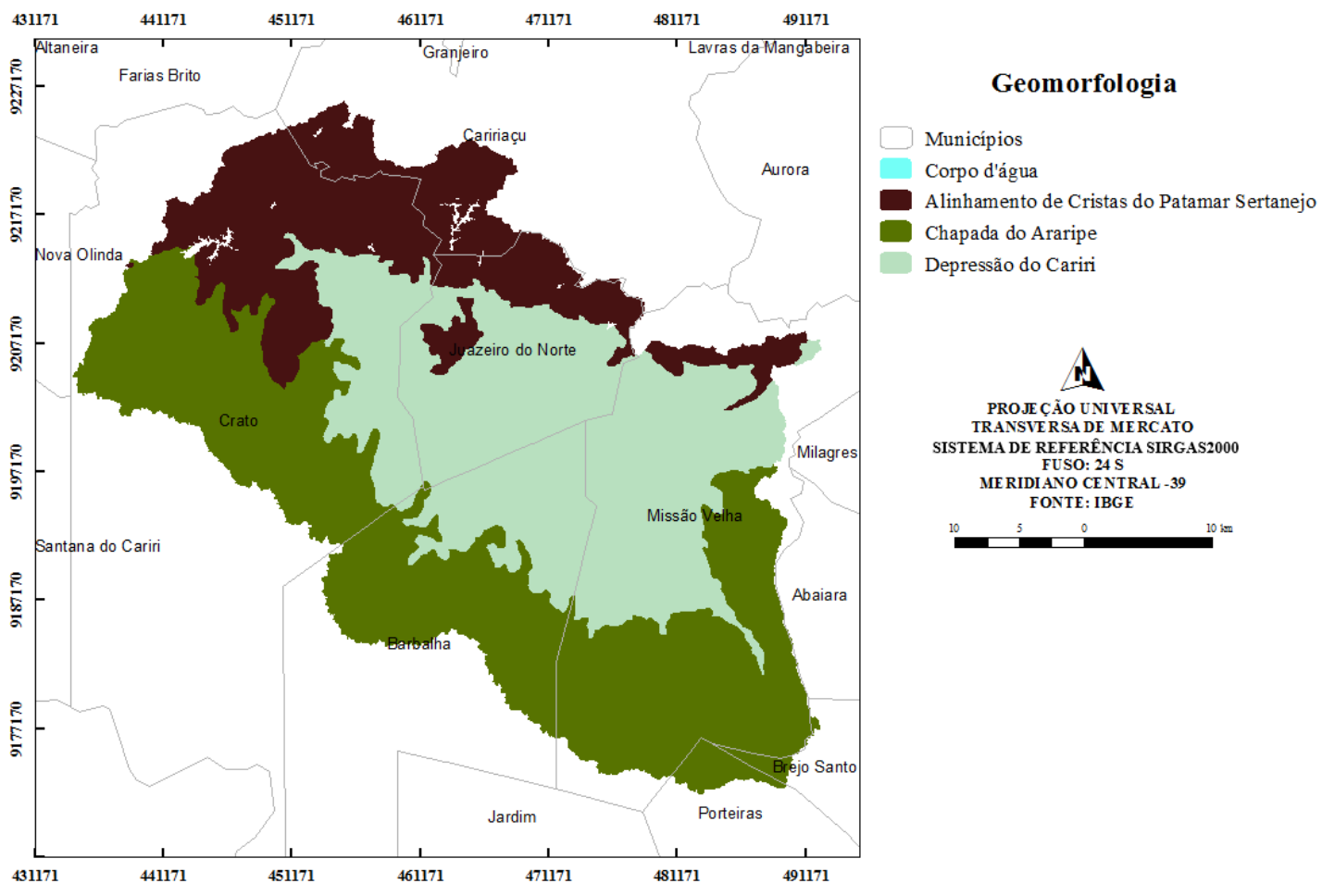

Fonte: Os autores (2021).

\subsection{Mapa de classes do solo}

Os Argissolos Vermelho-Amarelo e Neossolos Flúvicos dispostos em relevos planos, bem como os Latossolos são solos profundos e de aspecto maciço poroso. Os Argissolos são solos medianamente profundos a profundos, moderadamente drenados e altamente suscetíveis à erosão (EMBRAPA, 2006). Os neossolos que ocupam uma porção considerável na bacia (Figura 7) são praticamente destituídos de minerais primários pouco resistentes ao intemperismo (RADAMBRASIL, 1981). 
Figura 7 - Mapa da classe do solo.

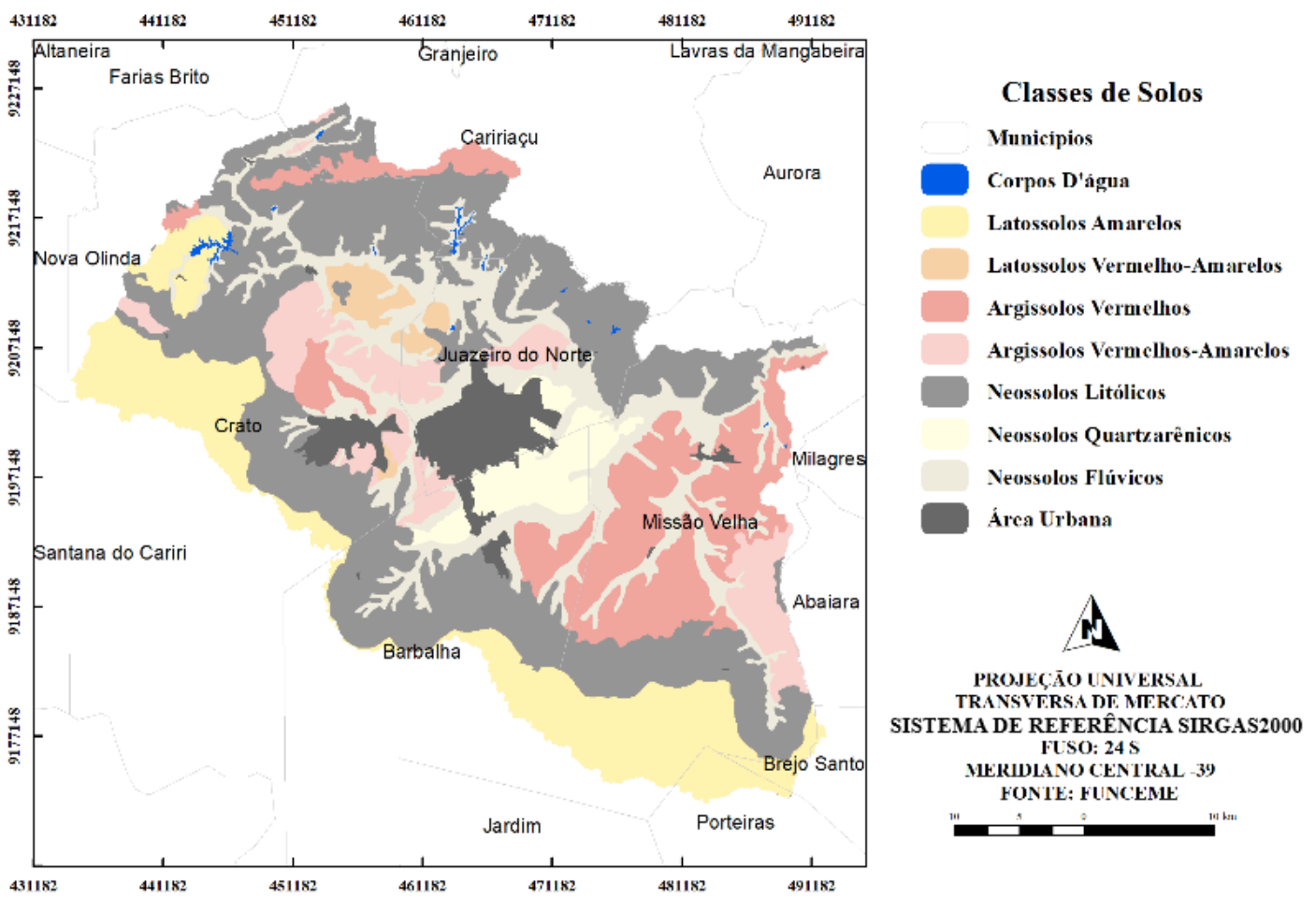

Fonte: Os autores (2021).

\subsection{Carta de suscetibilidade à erosão}

Por fim, a carta de suscetibilidade foi elaborada levando em consideração todas as variáveis anteriormente mencionadas e com uma resolução espacial de $30 \mathrm{~m}$. Observa-se que, as áreas consideradas com uma suscetibilidade muito forte correspondem às variáveis que receberam os pesos acima de oito, essa categoria totalizou uma área de $2,9 \mathrm{~km}^{2}$, nesses locais estão presentes as classes Chapada do Araripe topo tabular, vegetação florestal com áreas agrícolas, declividades maiores a 75\% e os solos Neossolos Litólicos, que quando possuem uma baixa profundidade, em relevos mais declivosos, apresentam forte suscetibilidade aos processos erosivos (Figura 8). 
Figura 8 - Carta de suscetibilidade à erosão da bacia estudada.

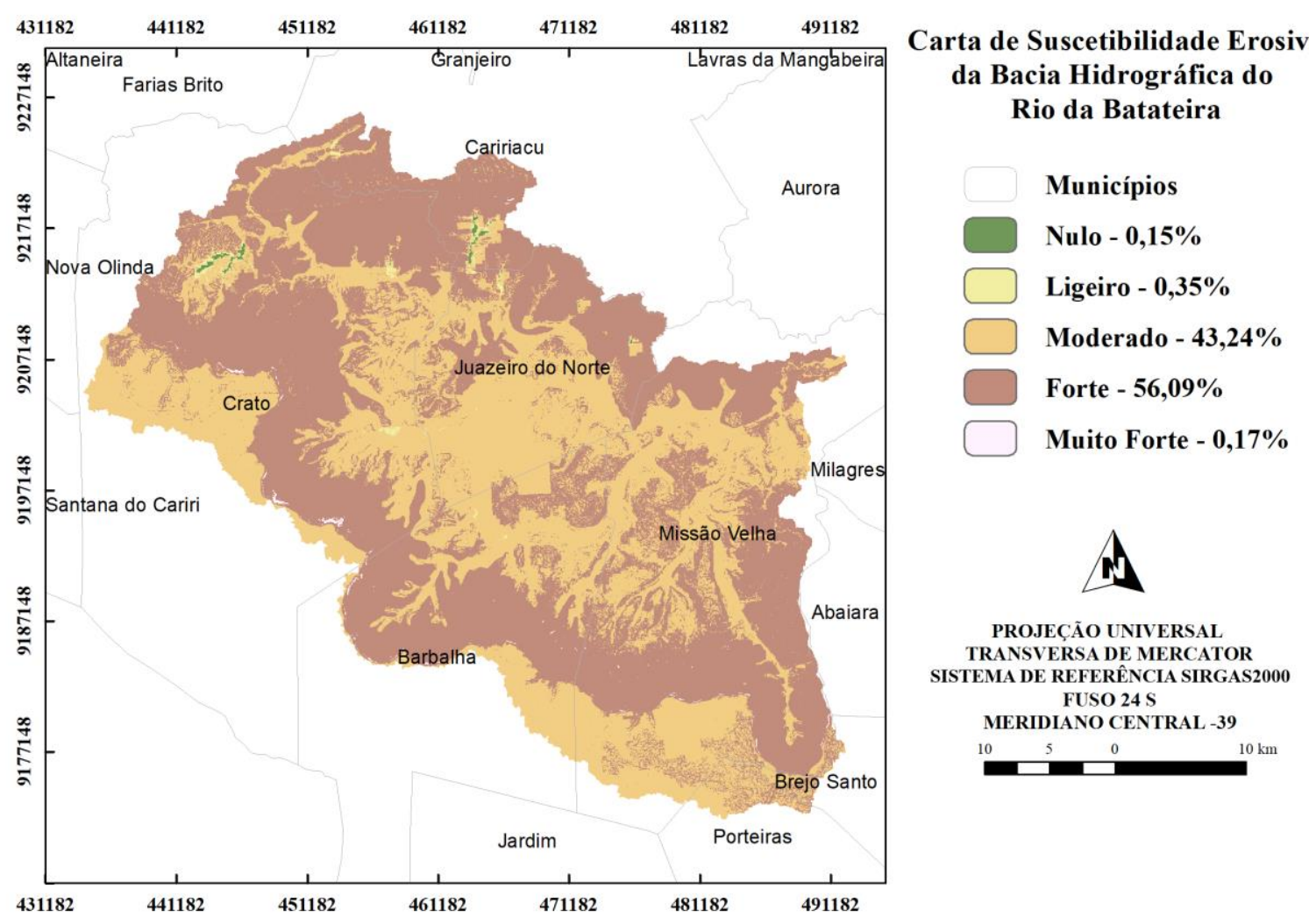

Fonte: Os autores (2021).

As regiões classificadas com suscetibilidade forte totalizaram uma área de $956,7 \mathrm{~km}^{2}$, representando mais de 56\% da área total, observa-se que essas áreas são marcadas pela presença de vegetação florestal e agrícolas, pastagem natural, além de áreas de agropecuária, o que contribui para essa suscetibilidade. Com declividades acima dos $20 \%$ os tipos de solos registrados são Argissolos Vermelhos, Vermelho-Amarelos, Latossolos Amarelos e Neossolos Quartzarênicos.

As áreas com suscetibilidade moderada $\left(737,6 \mathrm{~km}^{2}\right)$ somaram pouco mais de $43 \%$ do total. Nesta região observa-se vegetação florestal combinada com áreas agrícolas, áreas agrícolas e agropecuárias e ainda pastagem natural. As declividades variam de 8 a $20 \%$ e são registrados solos do tipo Latossolo Amarelo, Vermelho Amarelo, Argissolos Vermelhos, Vermelhos-Amarelos além de Neossolos Flúvicos.

Dessa maneira, pode-se observar a intensa suscetibilidade da área à erosão, sendo necessário implementar medidas de ação que possam melhorar e frear regiões que se encontram comprometidas.

\section{CONCLUSÕES}

A avaliação dos dados cartográficos e bibliográficos levantados sobre a área de estudo foi a primeira etapa e a mais árdua do processo, isso porque o estado do Ceará não apresenta cobertura de dados cartográficos atualizados, tampouco em escalas de detalhamento grande. A obtenção dos vetores das variáveis utilizadas foi uma tarefa demorada. Esforços de comunicação constante além de numerosos acessos a sites de instituições responsáveis por tal acervo digital foram atitudes recorrentes nesse procedimento inicial.

A análise da interação que a ocupação tem com o meio físico da região foi a última etapa do trabalho. Nessa fase, o mapeamento possibilitou ter uma proporção dos locais mais vulneráveis na Bacia Hidrográfica do rio da Batateira. Os resultados demonstraram que mais de $56 \%$ do local estudado são áreas com forte vulnerabilidade à erosão do solo, enquanto que quase $43 \%$ representam áreas de suscetibilidade moderada. As declividades acima de 8\%, assim como as classes Argissolos Vermelhos; Vermelhos Amarelos, Latossolos Amarelos; Neossolos Quartzarênicos e Litólicos são mais propícios à erosão.

A área de estudo apresenta uma grande área suscetível à erosão, o que torna necessário um manejo do 
solo adequado, o monitoramento e a adoção de práticas preventivas, bem como limitar a ocupação em encostas com declividade onduladas, reflorestar as cabeceiras e matas ciliares, conservando as áreas de preservação.

A carta pode oferecer auxílio à tomada de decisão, podendo contribuir em planos de gestão ambiental, o que proporciona alternativas futuras de manejo, além da conservação e recuperação dos solos da bacia, alertando o Poder Público da necessidade de um planejamento ambiental, que vise amenização do risco ambiental das terras, do uso do solo e do relevo.

Por fim, como sugestões para análises futuras, recomenda-se o estudo incluindo outras variáveis, como pluviometria, assim como a utilização de dados cartográficos em escalas maiores, para que o nível de detalhamento seja melhor, enriquecendo a análise, além de atividades ao campo, como visitas à área estudada.

\section{Agradecimentos}

As autoras agradecem à Universidade Federal Rural do Rio de Janeiro.

\section{Contribuição dos Autores}

As autoras contribuíram igualmente em todas as etapas de elaboração do artigo, desde sua conceptualização à edição e revisão do texto final.

\section{Conflitos de Interesse}

Os autores declaram que não há conflitos de interesse.

\section{Referências}

AHMED, CLARISSA REGINA MASIERO. Fatores que influenciam a erodibilidade nos solos do município de Campos dos Goytacazes-RJ sob uma análise multicritério. 2009. 108 f. Dissertação (Mestrado) - Curso de Engenharia Civil, Centro de Ciência e Tecnologia, Universidade Estadual do Norte Fluminense Darcy Ribeiro, Campos dos Goytacazes, RJ, 2009.

ASSINE, M. L. Análise estratigráfica da Bacia do Araripe, Nordeste do Brasil. Rev.Bras.Geoc., São Paulo, v. 22, p. 289-300, 1992.

ASSINE, M. L. Paleocorrentes e paleogeografia na Bacia do Araripe, Nordeste do Brasil. Rev.Bras.Geoc., São Paulo, v. 24, p. 223-232, 1994.

BASILIO, Thamiris Cristina Costa et al. Influência da Forma das Encostas na Suscetibilidade à Erosão na Bacia Hidrográfica do Rio Claro (Santa Rita do Passa Quatro, SP). Revista Brasileira de Cartografia, [s.1.], v. 71, n. 1, p.233-252, 29 mar. 2019. DOI.: 10.14393/rbcv71n1-2172.

BRASIL. Ministério das Minas e Energia. Departamento Nacional de Produção Mineral. Projeto Radambrasil. Folha SB.24/25 Jaguaribe/Natal. V. 23; geologia, geomorfologia. Rio de Janeiro: MME. SG, 1981.

CHAGAS, DANIEL BEZERRA DAS. Litoestratigrafia da Bacia do Araripe: REAVALIAÇÃO E PROPOSTAS PARA REVISÃO. 2006. 127 f. Dissertação (Mestrado) - Curso de Geologia, Instituto de Geociências e Ciências Exatas, Universidade Estadual Paulista, Rio Claro, 2006.

CHAPADA. Minidicionário Geográfico Online, 12 abr. 2017. Disponível em <https://geografesron.wordpress.com/2017/04/12/mini-dicionario-geografico/>. Acesso em 27 mai. 2019.

CEARÁ, Governo do Estado do. Diagnóstico e Macrozoneamento Ambiental do Estado do Ceará: Diagnóstico Geoambiental. v.1. Fortaleza: Convênio FCPC/Semace, 1998.

DINIZ, S. F.; Moreira, C. A.; Corradini, F. A. Susceptibilidade erosiva do baixo curso do rio Acaraú-CE., Geociênciencias, vol.27, n.3, pp. 355-367, 2008. 
EMPRESA BRASILEIRA DE PESQUISA AGROPECUÁRIA (EMBRAPA). Centro Nacional de Pesquisa de Solos. Sistema brasileiro de classificação de solos. 2. ed. Rio de Janeiro, 2006. 306 p.

EMPRESA BRASILEIRA DE PESQUISA AGROPECUÁRIA (EMBRAPA). Serviço Nacional de Levantamento e Conservação de Solos (Rio de Janeiro, RJ). Súmula da 10. Reunião Técnica de Levantamento de Solos. Rio de Janeiro, 1979. 83p.

FANTINEL, R. A.; BENEDETTI, A. C. P. Avaliação dos fatores influentes na vulnerabilidade à erosão solo por meio de decisão multicritério e de técnicas de geoprocessamento no município de Piratini-RS. Ciência e Natura, S.i., v. 38, n. 1, p.156-163, 2016.

FERREIRA, Joyce Clara Vieira et al. Atividade de Campo e o Ensino de Geografia Física: Uma Proposta de Roteiro Científico para a Chapada do Araripe, Ceará, NE do Brasil. Sociedade e Território, Natal, v. 28, n. $1, \quad$ p. 174-192, jun. 2016. Semestral. Disponível em: <https://periodicos.ufrn.br/sociedadeeterritorio/article/view/7733/7004>. Acesso em: 25 abr. 2019.

FUNDAÇÃO CEARENSE DE METEOROLOGIA E RECURSOS HÍDRICOS (FUNCEME). Levantamento de reconhecimento de média intensidade dos solos da Mesorregião do Sul Cearense. Fortaleza, 2012. 280p. Disponível em < http://www.funceme.br/?page_id=2787>. Acesso em: 07 jul. 2019.

FUNDAÇÃO CEARENSE DE METEOROLOGIA E RECURSOS HÍDRICOS (FUNCEME). Levantamento de reconhecimento de média intensidade dos solos da Mesorregião do Sul Cearense. MAPAS. Fortaleza, 2012. 98p. Disponível em <http://www.funceme.br/?page_id=2787>. Acesso em: 28 jun. 2019.

FUNDAÇÃO CEARENSE DE METEOROLOGIA E RECURSOS HÍDRICOS (FUNCEME). Compartimentação Geoambiental do Estado do Ceará. Fortaleza, 2009. 37 p. Disponível em <http://www2.ipece.ce.gov.br/atlas/capitulo1/12.htm>. Acesso em: 16 jul. 2019.

FUNDAÇÃO CEARENSE DE METEOROLOGIA E RECURSOS HÍDRICOS (FUNCEME).Caracterização das bacias hidrográficas do estado do Ceará. Fortaleza, 2009. Disponível

em https://www.bdpa.cnptia.embrapa.br/consulta/busca?b=ad\&id=1009332\&biblioteca=vazio\&busca=autor ia:\%22FUNCEME.\%22\&qFacets=autoria:\%22FUNCEME.\%22\&sort=\&paginacao=t $\&$ paginaAtual=1. Acesso em: 20 jul. 2019.

LAL, R. Erodibility and erosivity. In: LAL, R.(Ed.). Soil erosion research methods. Ankeny: Soil and Water Conservation Society Wageningen,1988. 244 p.

MANTOVANI, Vanessa Alves et al. Estimativas da Taxa de Entrega de Sedimentos e Áreas Suscepítveis à Erosão em uma Bacia Hidrográfica no Sul De Minas Gerais - BRASIL. Revista da Universidade Vale do Rio Verde, [s.1.], v. 16, n. 2, p.1-10, 2018. DOI.: 10.5892/ruvrd.v16i2.5061.

MENDONÇA, L. A. R. Recursos hídricos da Chapada do Araripe. 2001. 193 f. Tese (Doutorado) - Curso de Engenharia Civil, Departamento de Enga. Hidráulica e Ambiental, Universidade Federal do Ceará, Fortaleza, 2001.

RICKSON, R. J. et al. Input constraints to food production: the impact of soil degradation. Food Security, v. 7, p. 351-364, 2015. DOI.: 10.1007/s12571-015-0437-x

SILVA, T. A. Aspectos da gestão dos recursos hídricos na sub-bacia hidrográfica do rio salgado. 2017. TCC (Graduação) - Curso de Engenharia Ambiental, Campus Juazeiro do Norte, Instituto Federal de Educação, Ciência e Tecnologia do Ceará, Juazeiro do Norte, 2017. Cap. 7.

SILVEIRA, L. L. L. Elaboração de Carta de Suscetbilidade à Erosão das Bacias dos rios Araraquara e Cubatão-SP, Escala 1:50.000. 2002. 211 f. Dissertação (Mestrado) - Curso de Geologia, Geotecnia, Universidade de São Carlos, São Carlos, 2002.

SOUZA, V. A. S. de et al. Processo de ocupação antropica e seu reflexo na susceptibilidade erosiva na bacia hidrográfica do Rio Machadinho-RO. In: SIMPÓSIO DE RECURSOS HÍDRICOS, 2015, S.i. Anais.... Si.: Ecoporé, 2015. v. 1, p. 1 - 20. 
SUSTAINABLE AGRICULTURE AND SOIL CONSERVATION (SOCO). Processos de degradação do solo. Ficha Informativa no 2. 2009.

VALÉRIO, F. M.; ARAÚJO, Jr. G. J. L. Técnicas de Geoprocessamento e Modelagem Aplicadas no Monitoramento de Áreas Submetidas aos Processos de Erosão do Solo. In: Anais do $5^{\circ}$ Simpósio Nacional de Controle de Erosão; 1995; Bauru-SP. 1995, p. 279-82.

VALLADARES, G. S.; GOMES, A. S.; TORRESAN, F, H.; RODRIGUES, C. A. G.; GREGO, C. R. Modelo multicritério aditivo na geração de mapas de suscetibilidade à erosão em área rural. Pesquisa Agropecuária Brasileira, v. 47, n. 9, p.1376-1383, 2012.

XAVIER, F. V. et al. Análise da suscetibilidade à erosão laminar na bacia do rio manso, Chapada dos Guimarães, MT, utilizando Sistemas de Informações Geográficas. Revista Brasileira de Geomorfologia, v. 11, n. 2, p.51-60, jul. 2010.

\section{Biografia dos autores}

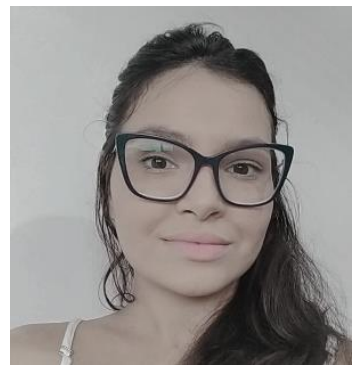

Rafaela Maria Rodrigues Tavares Agra, natural de Juazeiro do Norte, Ceará, nascida em 10 de maio de 1993. Graduada em Engenharia de Agrimensura e Cartográfica pela Universidade Federal Rural do Rio de Janeiro, UFRRJ (2017).

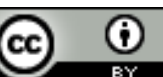

Esta obra está licenciada com uma Licença Creative Commons Atribuição 4.0 Internacional - CC BY. Esta licença permite que outros distribuam, remixem, adaptem e criem a partir do seu trabalho, mesmo para fins comerciais, desde que lhe atribuam o devido crédito pela criação original. 